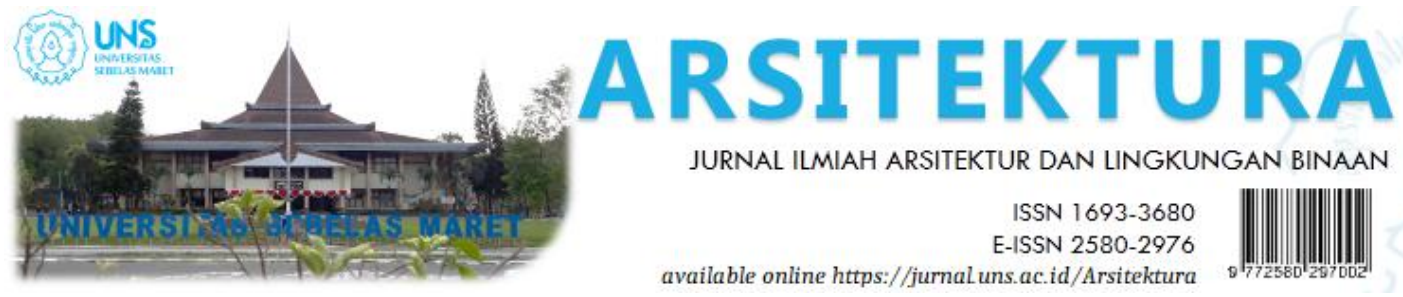

Volume 17 Issue 2 October 2019, pages:221-230

\title{
Penerapan Fleksibilitas Sebagai Strategi Desain Perancangan Kampung Kota Vertikal Kenteng Semanggi, Surakarta
}

\section{Application of Flexibility as a Design Strategy of Vertical Kampung Kota Kenteng Semanggi}

\author{
Amalia Ji Darmastuti ${ }^{1 *}$, Yosafat Winarto ${ }^{2}$, Hardiyati ${ }^{3}$ \\ Architecture Department, Engineering Faculty, Sebelas MaretUniversity ${ }^{1 *}$ \\ Email : amaliaajd@gmail.com* \\ Architecture Department, Engineering Faculty, Sebelas MaretUniversity ${ }^{2}$ \\ Architecture Department, Engineering Faculty, Sebelas MaretUniversity ${ }^{3}$
}

DOI: https://doi.org/10.20961/arst.v17i2.24368

Received: October 1, 2018 Revised: October 28, 2018 Accepted: March 30, 2019 Available online:October 31, 2019

\begin{abstract}
Dwelling is not only about a solid building, but also the activity system. Squatter Dwelling or kampong has varies identity and one can be described from their spaces usage colerated with their activity. It can be seen with substantial changes in the house users, their daily needs, economical reason, and their cultural environment. The research takes a case study in Kampung Kenteng, Kelurahan Semanggi, Kecamatan Pasar Kliwon, Surakarta. This research aims to signify flexibility values as design strategy by discover the use of compact housing as a multifunctional and adaptable space which can acomodate the needs of daily and economical living in limited space of Kampung with the creative use of flexibility. This paper present a comperhensive review of eleven points of flexibility which are permeability, versatility, legibility, expandibility, convertibility, adaptable, transformable, moveable, time cycle and time management, continuity and stability, and implemented over time. Furthermore, the theory will be implemented in the design of Vertical Kampung Kota Kenteng Semanggi to reveal how flexibility takes an important role in the arrangement of spaces usage in squatter housing with the possibility to expand and respond to changes.
\end{abstract}

Keywords: spaces usage, flexibility, vertical kampong kota

\section{PENDAHULUAN}

Permukiman ilegal adalah salah satu masalah besar di kota-kota besar. Masyarakat cenderung berpindah dari perdesaan ke perkotaan untuk memenuhi kebutuhan sehari-hari karena daerah perkotaan memiliki kesempatan kerja lebih banyak daripada daerah perdesaan, terutama di negara berkembang. Salah satu daerah di mana kaum urban terutama keluarga berpenghasilan menengah ke bawah menetap adalah lahan marjinal atau squatter. Lahan marjinal adalah area yang dimiliki oleh pemerintah atau tidak memiliki klaim hukum yang jelas.

Masyarakat yang tinggal di tanah marginal biasanya menghuni rumah sederhana yang harus dapat mengakomodasi kegiatan seharihari mereka dan kebutuhan ekonomi mereka. Penelitian ini bertujuan untuk melihat keterhubungan antara kebutuhan ruang dan penggunaan nilai-nilai kreatif dari fleksibilitas yang terjadi di perumahan liar dan bagaimana perumahan dapat beradaptasi di tanah ilegal 
yang memiliki permasalahan penggusuran. Penulis tertarik untuk memperluas relevansi kehidupan di lahan squatter dan nilai-nilai fleksibilitas sebagai strategi desain Vertikal Kampung Kota Kenteng Semanggi yang berlokasi di Kampung Kenten, Kota Surakarta.

Kota Surakarta sendiri memiliki lima area permukiman ilegal yang diprioritaskan oleh pemerintah sebagai area implementasi pengentasan kemiskinan, berdasarkan program nasional 100-0-100 (100 air bersih-0 kemiskinan-100 sanitasi). Kelurahan semanggi menjadi prioritas utama dan salah satu daerah terpilih adalah Kampung Kenteng Semanggi yang terletak di bagian paling selatan Kota Surakarta. Kampung Kenteng adalah pemukiman yang tumbuh di tanah yang dimiliki oleh pemerintah Kota Surakarta (HP 16). Dapat dilihat pada Gambar 1, Kampung ini memiliki 6 RT dengan 4 RT di antaranya berada di tanah pemerintah dihuni oleh $\pm 490 \mathrm{KK}$ dan memiliki beragam tipe aktivitas dan usaha rumahan seperti kerajinan rumahan, percetakan, warung, kuliner, penjahit, dan bengkel. Kondisi kependudukan mayoritas illegal KTP solo dan fisik lingkungan mayoritas semi permanen.

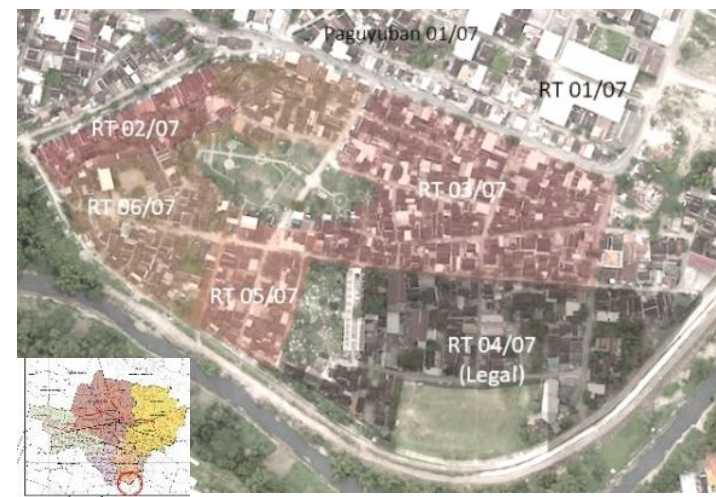

Gambar 1. Batas lokus penelitian

Kampung Kota Vertikal menjadi objek pengaplikasian nilai-nilai fleksibilitas karena konsep ini dianggap sebagai salah satu solusi yang dapat menjawab permasalahan kebutuhan hunian. Selain dapat menjadikan tata ruang kampung yang lebih baik, konsep vertikal juga mampu membuka ruang terbuka baru sebagai area hijau dan area resapan air menurut Yanno (2016).

Dalam pemenuhan kebutuhan sehari-hari dan alasan ekonomi, penghuni Kampung Kenteng menggunakan rumah mereka sendiri sebagai ruang multifungsi dengan kreativitas mereka sendiri untuk membuat rumah mereka dapat sefleksibel mungkin.

Nilai fleksibilitas diambil sebagai strategi desain berdasarkan hal yang menjadi temuan di lapangan dan diharapkan dapat menjawab kebutuhan ruang yang fleksibel untuk masyarakat Kampung Kenteng.

Penerapan fleksibilitas sebagai strategi desain berupa implementasi dari beberapa teori fleksibilitas di bawah ini:

Teori pertama oleh Bentley et al (2003) dalam fleksibilitas ruang perkotaan dengan Permeability yang diimplementasikan dalam kemampuan untuk mengidentifikasi potensi situs sebagai akses pusat, Versatility di ruanpublik multifungsi, dan Legibility dalam konsep pencarian jalan atau way-finding.

Teori kedua oleh Toekio (2000) dengan Expandibility yang diaplikasikan dalam kemungkinan untuk memperluas area, Convertibility dalam kemampuan untuk beradaptasi tanpa perlu merombak, dan Versatility dalam kemampuan untuk berubah menjadi ruang multifungsi dalam waktu yang berbeda.

Teori ketiga oleh Aishwarya (2003) dengan Adaptable yang diaplikasikan dalam sistem denah terbuka atau open plan, Transformable dalam struktur yang dapat diubah. Moveable dengan kemampuan untuk dapat memindahkan dan dan merubah struktur, Interactive dalam cara bangunan dapat merespon energi lingkungan.

Teori terakhir oleh Carmona et al (2003) dalam Temporal Dimension dengan Time Cycle and Time Management yakni waktu yang diimplementasikan dalam ruang yang fleksibel yang dapat mengakomodasi berbagai kegiatan, Continuity and Stability dalam membangun adaptasi dengan lingkungan, dan Implemented over time dalam kemampuan untuk beradaptasi dengan perubahan antara pengguna dan sekitarnya.

\section{METODE}

Penelitian ini menggunakan pengumpulan data primer dan sekunder dengan melakukan observasi lapangan, penelitian sederhana, dan 
Amalia Ji Darmastuti, Yosafat Winarto, Hardiyati, Penerapan Fleksibilitas Sebagai Strategi Desain....

studi literatur. Pola pikir penelitian dapat dilihat pada Tabel 1.

Tabel 1. Metode

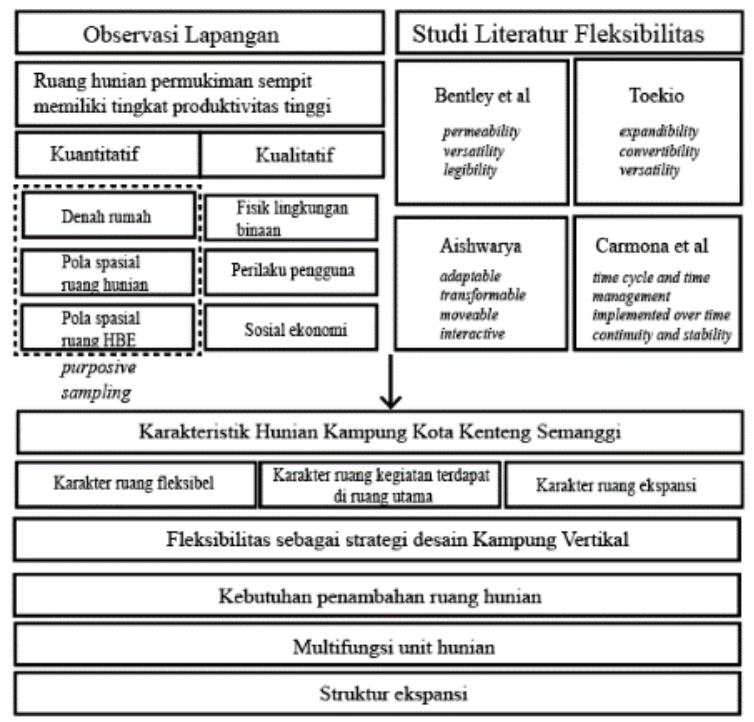

\subsection{Pengumpulan Data Primer}

Pengambilan data melalui metode kualitatif dan kuantitatif. Kualitatif dilaksanakan dengan survey langsung wilayah Kampung Kenteng, untuk mendapatkan hasil yang valid meliputi kondisi permukiman, fasilitas sosial, perilaku, perekonomian, dan sebagainya. Pengumpulan data kuantitatif seperti jumlah penduduk dan jumlah penghasilan warga. Data primer juga didapatkan dengan penelitian sederhana mengenai tipologi penggunaan ruang hunian di permukiman dengan metode purposive sampling.

\subsection{Pengumpulan Data Sekunder}

Studi literatur mengenai teori fleksibilitas dan Kampung Vertikal serta studi preseden mengenai aplikasi nilai-nilai fleksibilitas dalam banguna yang telah ada.

\subsection{Pengolahan data atau visualisasi data}

Data yang telah didapatkan kemudian diproses melalui analisis data, pengolerasian data dan teori, serta aplikasi teori fleksibilitas sebagai strategi desain Kampung Kota Vertikal. Teori kemudian diaplikasikan ke dalam lima aspek desain yakni massa, ruang, struktur, akses, dan utilitas.

\section{HASIL DAN PEMBAHASAN}

Kampung Kenteng memiliki dinamika yang cukup menarik dengan $80 \%$ dari warganya memiliki profesi industri rumahan atau home based enterprises. Hasil observasi denah dan pola ruang hunian di permukiman Kampung Kenteng dapat dilihat pada Gambar 2.

Berdasarkan data tersebut, ditemukan bahwa ruang utama memiliki peran yang sangat tinggi dalam pemenuhan kebutuhan ruang hunian dan ruang ekonomi. Ruang utama menjadi core dalam hunian sehingga menjadi pusat yang menghubungkan ruang-ruang lainnya.

Ruang hunian di Kampung Kenteng juga memiliki area depan dan samping hunian yang menjadi area ekspansi untuk kebutuhan perekonomian seperti warung dan area produksi, sehingga dapat disimpulkan jenis penggunaan ruang hunian untuk pemenuhan kebutuhan sehari-hari dan aktivitas ekonomi terbagi ke dalam tiga tipe yang dapat dilihat pada Gambar 2.
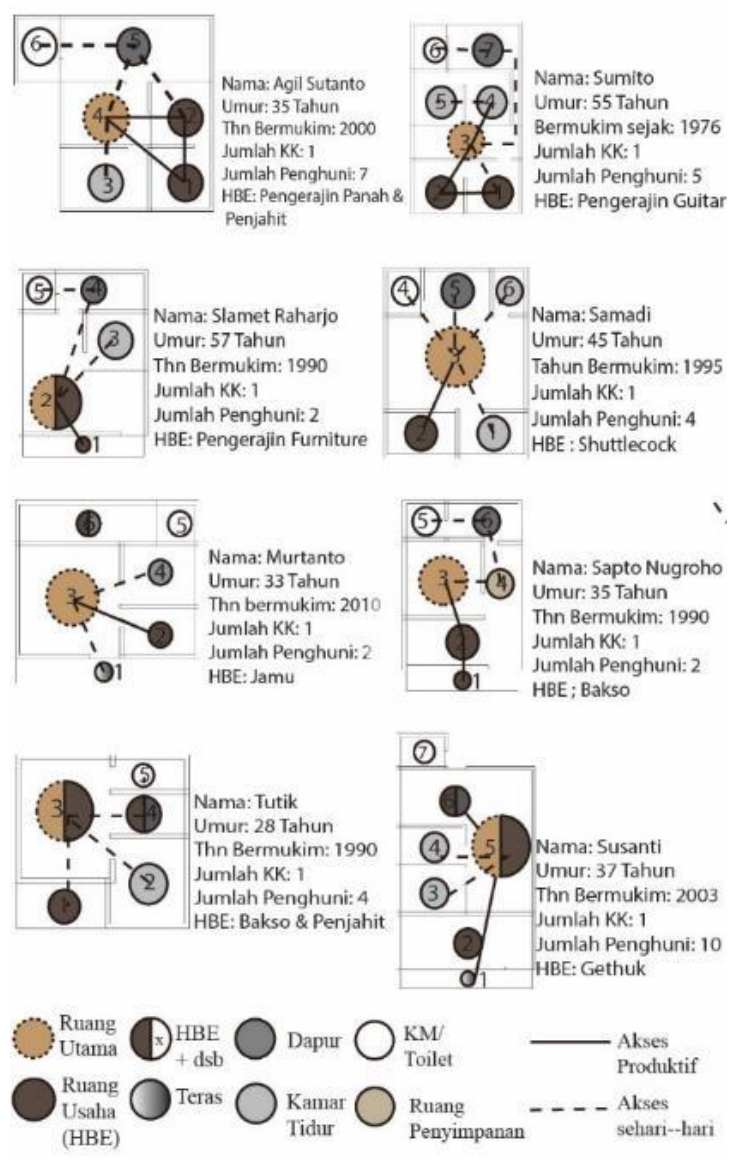

Analisis spasial ruang hunian Kampung Kenteng 


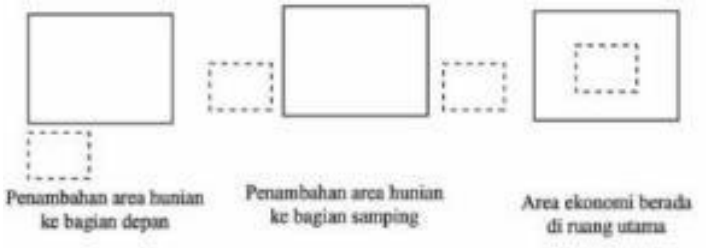

Gambar 2. Analisis spasial ruang hunian Kampung Kenteng

Hasil analisis diatas kemudian menjadi landasan penerapan fleksbilitas sebagai strategi desain unit hunian. Penerapan teori fleksibilitas dalam desain akan diturunkan ke dalam lima aspek yakni akses, bentuk bangunan, ruang, struktur, dan utilitas yang akan dijelaskan di bawah ini:

\subsection{Fleksibilitas Dalam Akses}

Fleksibilitas sebagai strategi desain muncul dalam akses kawasan dengan kemudahan akses dan pencapaian bagi pengguna permukiman. Upaya tersebut diwujudkan dalam penatan bentuk bangunan yang memiliki pola grid yang dapat dilihat pada Gambar 3.

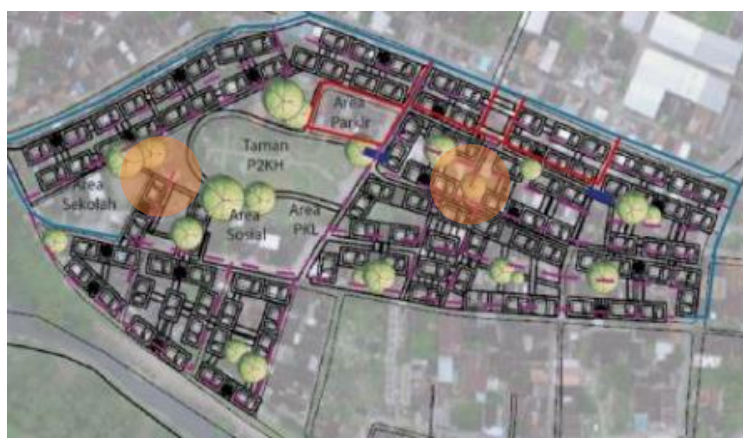

Gambar 3. Akses Kawasan

Penataan massa berbentuk grid untuk mempermudah akses kawasan terutama pedestrian sehingga membentuk sistem wayfinding yang mempermudah pejalan kaki mengakses area atau massa tertentu secara horizontal maupun vertikal. Akses vertikal menggunakan dua ramp utama dan connector antar bangunan yang dapat dilihar pada gambar 4. Konsep ini berdasarkan poin teori Legibility oleh Ian Bentley.

Poin legibilitas juga memiliki keterhubungan dengan poin Permeability yang pada desain diwujudkan dengan sentralisasi kawasan. Akses pada permukiman berpusat menuju taman P2KH yang kemudian menjadi titik temu atau titik sentral dari kawasan. Poin ini diwujudkan agar pengguna permukiman dapat mengakses area dengan mudah dan fleksibel.

Potensi taman P2KH kemudian didukung dengan adanya area sosial serbaguna yang berada di arah barat daya taman P2KH. Area sosial tersebut berupa balai desa, masjid, dan gereja yang dapat dibongkar pasang sesuai dengan kebutuhan berdasarkan dengan poin Versatility oleh Bentley et al (2003).

Berikut merupakan pola sirkulasi pedestrian dalam mengakses permukiman baik di dalam maupun ke luar permukiman. Pola sirkukasi menyesuaikan tatanan massa yang berpola grid dan memiliki kemudahan akses menuju antar bangunan dan menuju titik sentral permukiman.
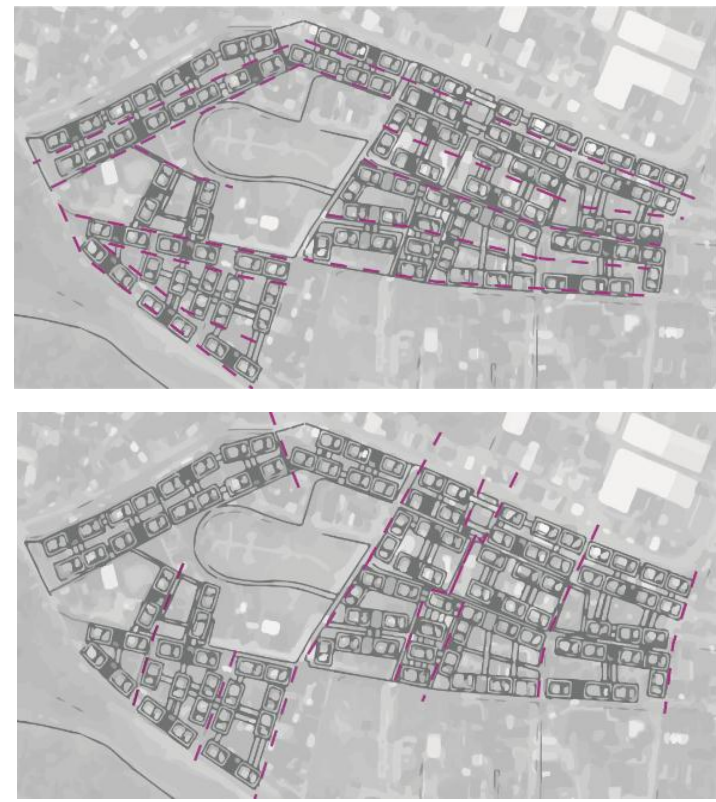

Gambar 4. Pola akses pedestrian

\subsection{Fleksibilitas Dalam Massa bangunan}

Bentuk bangunan menggunakan bentuk geometris kotak karena bentuk kotak memiliki tingkat fleksibel tertinggi dibandingkan dengan bentuk geometris lainnya sehingga mudah untuk digubah, dibentuk, dan disesuaikan dengan kondisi tapak Kampung Kenteng.

Selain mempertimbangkan bentuk tapak, bentuk bangunan juga mempertimbangkan kondisi lingkungan berdasarkan poin Continuity and Stability oleh Carmona et al (2003). Tatanan massa bangunan ditata dengan kemiringan $20^{\circ}$ arah timur laut sehingga memilliki akses matahari pagi (timur) cukup 
maksimal. Massa dibuat berbeda tingkat ketinggian sehingga dapat memaksimalkan cahaya masuk hingga ke dasar bangunan. Massa dibuat memiliki gap antar unit hunian sehingga cahaya dapat menyebar hingga ke seluruh bangunan (lihat pada Gambar 5).

Massa bangunan juga berpengaruh pada akses angin. Kemiringan $20^{\circ} \mathrm{ke}$ arah Timur laut juga memberikan potensi angin yang cukup baik melihat angin yang berhembus dari arah Tenggara. Gap antar unit hunian juga membantu dalam kelancaran aliran angin dan mempermudah pendistribusian udara ke unit hunian. (lihat pada Gambar 5).

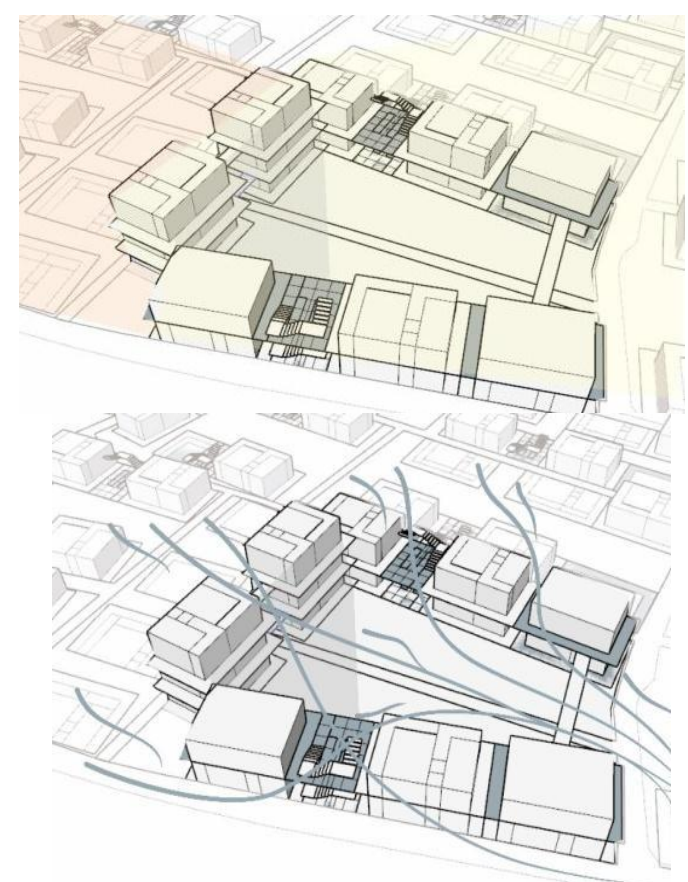

Gambar 5. Bentuk bangunan berdasarkan kondisi cahaya matahari dan angin

\subsection{Fleksibilitas Dalam Ruang}

Dalam pemenuhan kebutuhan ruang hunian. Fleksibilitas sebagai strategi desain muncul ke dalam beberapa poin di bawah ini:

Poin adaptable oleh Aishwarya (2013) muncul dalam bentuk sistem open plan atau denah terbuka sehingga unti hunian tidak memiliki ruang-ruang permanen tertentu.

Berkaitan dengan poin adaptable, poin Time cycle and time management oleh carmona et al (2003) diturunkan dalam bentuk ruang fleksibel yang dapat menyesuaikan aktivitas sehingga konsep ruang hunian berupa ruang hunian modular $1,5 \mathrm{~m} \times 1,5 \mathrm{~m}$ yang dapat diubah dan disesuaikan dengan kebutuhan pengguna. Ruang hunain kemudian hadir ke dalam tiga tipe yang dapat dihilihat pada Gambar 6 .

Berdasarkan poin expandibility oleh Toekio (2000), ruang hunian modular memiliki ruang utama dan ruang ekspansi sehingga ruang utama dapat menjadi inti unit hunian dan hunian yang dapat dilihat pada Gambar 7 memungkinkan adanya ekspansi sesuai dengan kebutuhan sehari-hari maupun kebutuhan ekonomi.

Poin moveable oleh Aishwarya juga hadir dalam bentuk partisi yang dapat dipindah dan diubah sesuai dengan kebutuhan ruang. Partisi dapat digunakan secara vertikal maupun horizontal (split level) namun dengan limitasi yang telah ditentukan.

Poin versatility oleh Toekio (2000) hadir dalam bentuk keseluruhan ruang hunian yang dapat menjadi ruang multifungsi yakni untuk pemenuhan kebutuhan hunian dan ekonomi dan penggunaan furniture multifungsi.

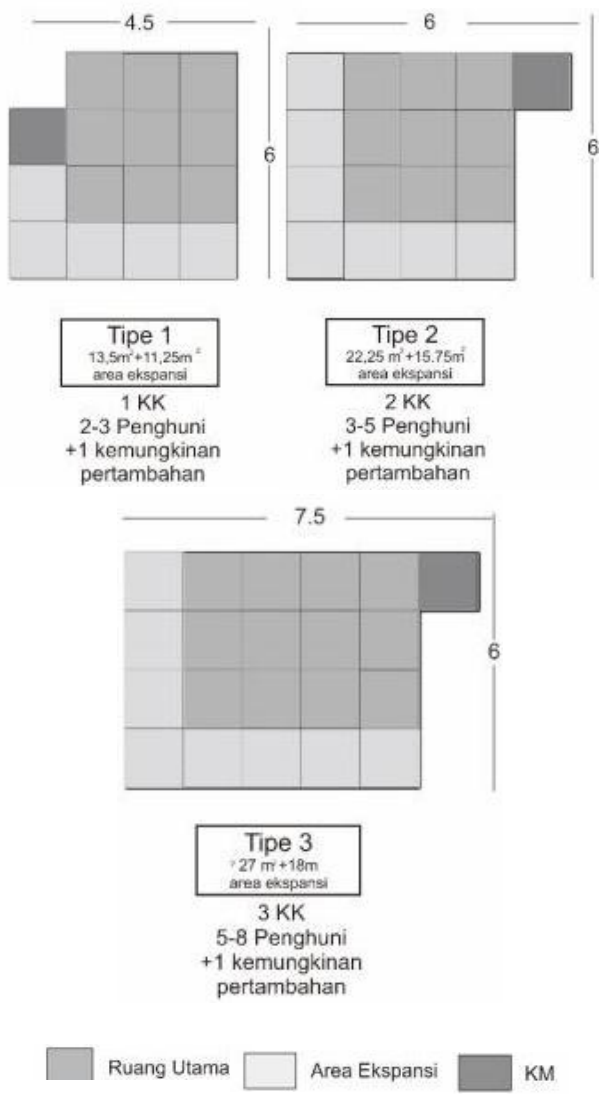

Gambar 6. Tipe unit hunian 
Penerapan nilai versatility juga muncuk ke dalam ruang luar hunian berupa area sosial yang dapat disesuaikan (adjustable social area). Area ini merupakan area gap diantara unit hunian yang dapat dimanfaatkan sebagai area terbuka, area sosial, maupun area ekonomi.

Penyesuaian area sosial ini juga dapat dimanfaatkan dengan partisi sebagai area duduk dalam penggunaan sebagai area sosial atau partisi sebagai kios/warung untuk area ekonomi, dapat dilihat pada Gambar 8.

Jalur akses yang terdapat di antara bangunan dapat dimanfaatkan sebagai area kandang. Struktur bangunan yang juga menggunakan tiang khusus sebagai kuncian partisi akan dimanfaatkan sebagai area penempatan kandang.

Kandang dibuat modular seperti puzzle sehingga dapat dipindah dan ditambahkan sesuai kebutuhan dan dapat dipasang sesuai dengan modul partisi tiang bangunan. Hal ini sebagai pemenuhan kebutuhan kandang yang menjadi salah satu karakteristik permukiman Kampung Kenteng, dapat dilihat pada Gambar 9.
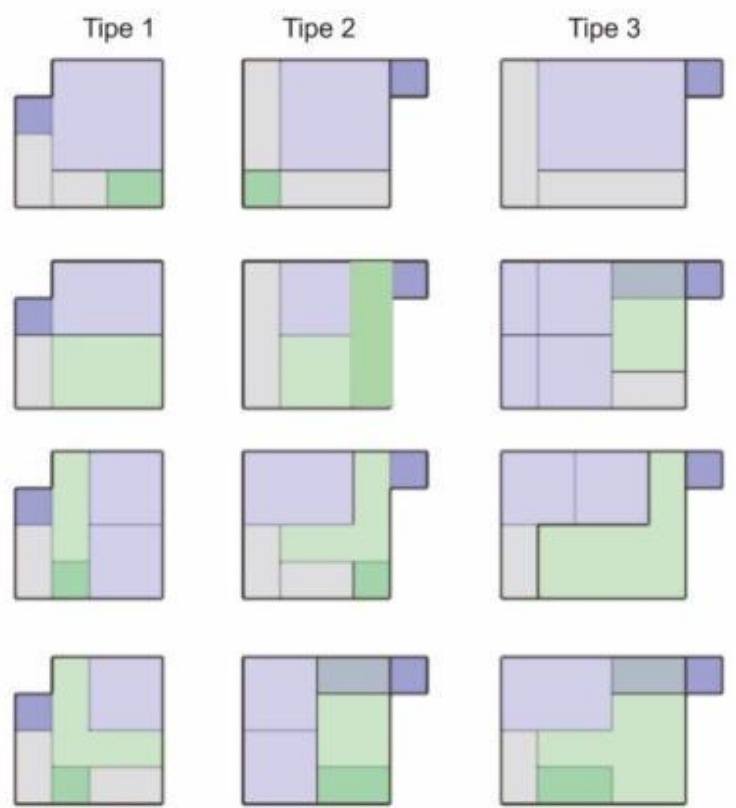

R.Utama $\square$ K. Tidur Dapur $\square$ R.Ekonomi $\square$ Teras $\square$ KM
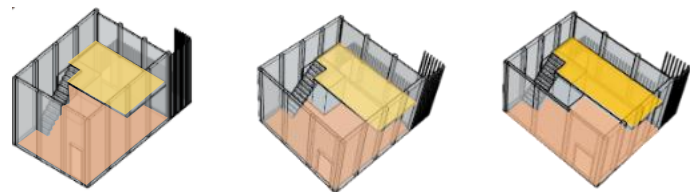

Gambar 7. Skenario Kemungkinan Ekspansi

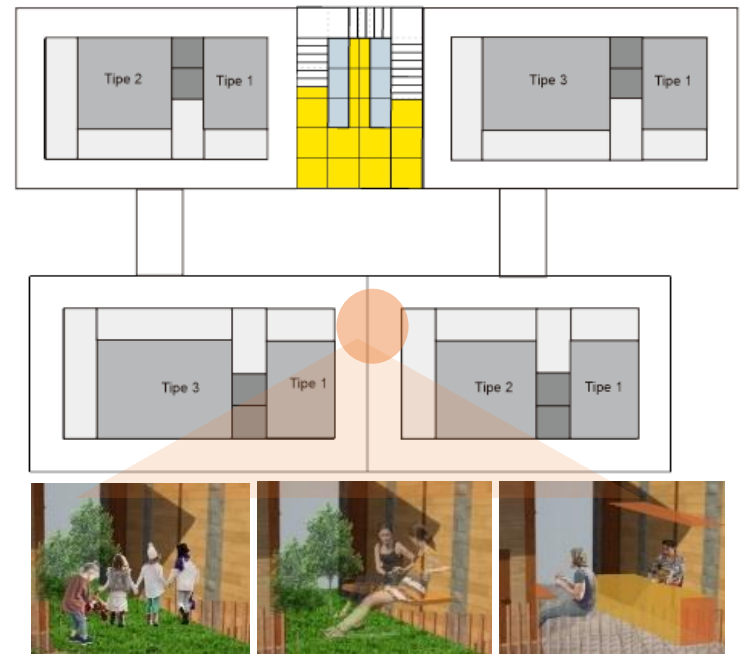

Gambar 8. Adjustable Social Area

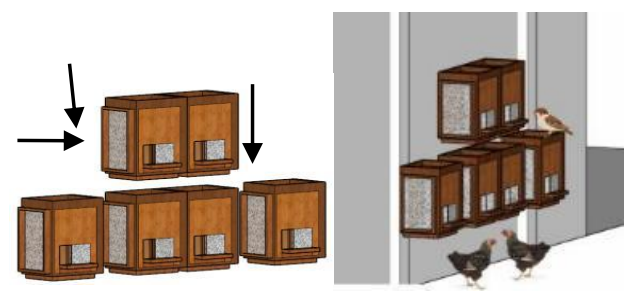

Gambar 9. Area Kandang

\subsection{Fleksibilitas Dalam Struktur}

Sistem struktur yang digunakan menganut poin fleksibilitas Implemented over time oleh Carmona et al (2003), sehingga dapat menyesuaikan dengan perubahan bangunan dan penggunanya. Poin convertibility oleh Toekio (2000) dengan perubahan tanpa harus merombak total, dan poin Transformable oleh Aishwarya (2013) dengan struktur yang dapat diubah.

Sistem struktur yang digunakan adalah sistem skeleton infill dengan adanya struktur utama dan struktur isian yang bekerja terpisah (open frame). Sistem utama dibagi menjadi dua sistem yakni struktur bangunan hunian dan bangunan sosial.

Struktur bangunan hunain menggunakan struktur sistem C plus. Sistem ini memiliki kelebihan dalam segi efisiensi pemasangan dan efisiensi luasan peruangan. Sistem ini terdiri dari komponen balok precast dan kolom precast yang dihubungkan dengan plat baja, besi, dan mur kemudian ditutup dengan semen 
tidak susut. Sistem strutur c-plus dapat dilihat pada Gambar 10a.

Struktur bangunan sosial menggunakan struktur RISHA (Rumah Instan Sederhana dan Sehat) yakni struktur puzzle untuk bangunan dua lantai. Struktur ini memiliki sistem panel beton yang dihubungkan sambungan kering mur dan baut sehingga memungkinkan adanya ekspansi ruang. Dapat dilihat pada Gambar 10b.

Struktur utama kemudian dipadukan dengan struktur isian berupa partisi yang memiliki modul 1,5 m sesuai dengan modul unit hunian. Struktur isian berupa partisi diaplikasikan dalam struktur bangunan hunian dan struktur bangunan sosial. Material partisi berupa multipleks dengan ketebalan $8 \mathrm{~mm}$ yang dipadukan dengan insulation.

Partisi dapat dipindah dan disesuaikan dengan kebutuhan luas ruang dan fungsi ruang. Partisi menggunakan sistem kuncian dengan tiang partisi yang dipasang pada kolom bangunan (Gambar 11). Hal tersebut diwujudkan sesuai dengan poin teori Convertibility oleh Toekio (2000) dan Transformable oleh Aishwarya (2013) yang mana pada kedua teori tersebut menegaskan bahwa fleksibilitas hadir dalam kemudahan merespon kemungkinan perubahan yang dialami oleh lingkungan dan pengguna.

Nilai fleksibilitas juga diwujudkan dalam pemenuhan kebutuhan jangka panjang dengan skenario penggunaan struktur modul untuk penambahan jumlah pengguna Kampung Kota Vertikal.

Kampung Kota Vertikal Kenteng Semanggi pada dasarnya dirancang untuk memenuhi kebutuhan warga Kampung Kenteng khususnya RT 02,03,05, dan 06, namun tidak menutup kemungkinan adanya pertambahan penduduk yang berasal dari permukiman kumuh Kelurahan Semanggi lainnya.

Strategi desain fleksibilitas juga muncul ke dalam penggunaan fasad. Fasad pada bangunan kampung vertikal mengadapatasi bentuk dan material dari kampung eksisting dimana pada Kampung Kenteng terdapat keberagaman fasad dan penggunaan material dari setiap rumah. Aplikasi bentuk fasad diwujudkan dalam penggunaan bentuk atap, jendela, pintu, dan material dari rumah tinggal dapat dimanfaatkan lagi di hunian kampung yang baru.
Hal ini menganut poin teori fleksibilitas convertibility oleh Toekio (2000) sehingga perubahan yang terjadi tidak sepenuhnya merombak atau mengganti dengan hal baru. Cara ini juga sebagai cara agar sky-line dan karakteristik kampung tetap terjaga.

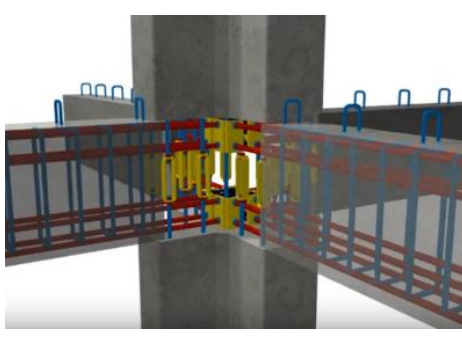

a

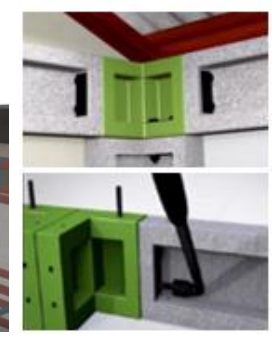

b
Gambar 10. Sistem struktur c-plus dan RISHA Sumber: PUSLITBANG

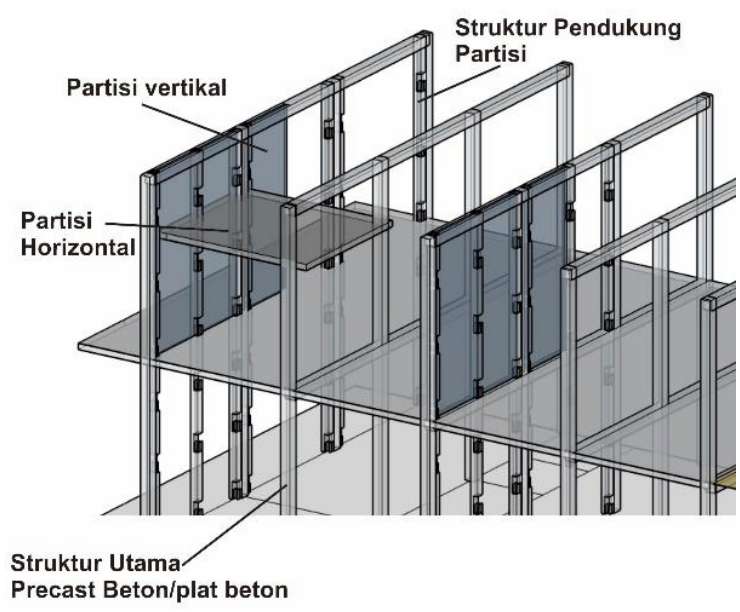

Gambar 11. Sistem struktur utama dan infill
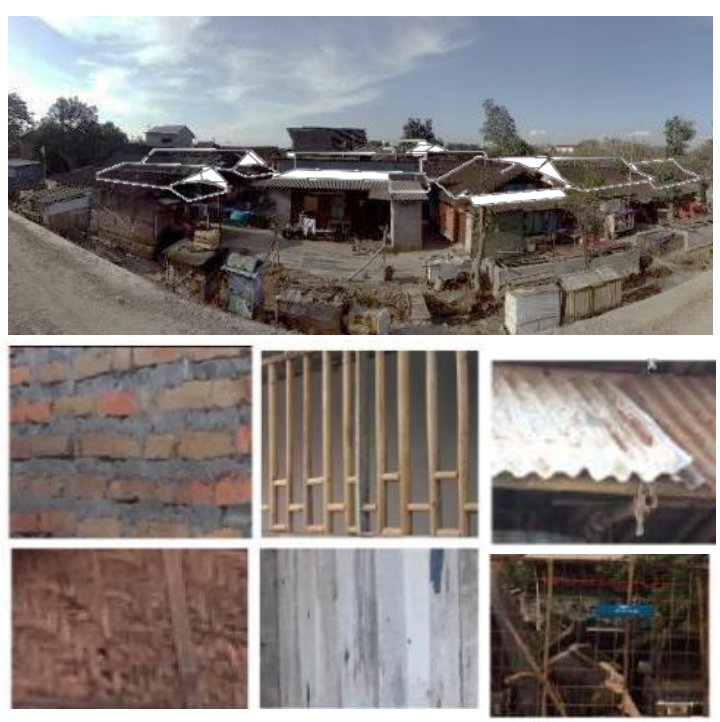

Gambar 12. Adopsi bentuk atap dan material lama 


\subsection{Fleksibilitas Dalam Utilitas}

Strategi desain dalam utilitas diwujudkan dalam poin Interacive oleh Aishwarya (2013), dimana bangunan harus dapat merespon energi lingkungan.

Kampung Kenteng memiliki topografi yang cenderung landai dengan kemiringan ke arah sungai yang berada di arah selatan Kampung Kenteng.

Letak Kampung Kenteng yang berada di bantaran Sungai Bengawan Solo dan memiliki tipe tanah gambut atau tanah rawa, menjadi penyebab kemungkinan banjir. Banjir yang melanda Kampung Kenteng tidak hanya bersumber pada sungai namun juga bersumber pada air sungai yang menyerap dan kembalik ke permukaan melalui saluran air di permukiman.

Hal tersebut kemudian diwujudkan dalam desain utilitas air yakni sistem pencegah banjir dan sistem air bersih yang memanfaatkan potensi air sungai.

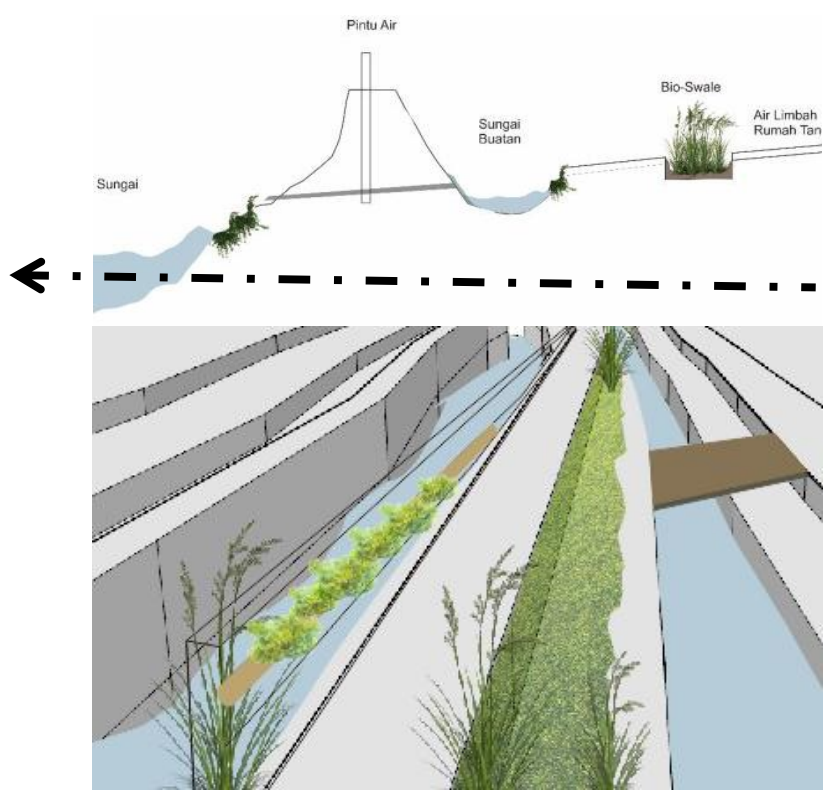

Gambar 13. Sistem Bio-Swale dan Sungai Buatan

Energi lingkungan dapat direspon dengan sistem pencegah banjir menggunakan sistem bio-swale. Sistem bio-swale merupakan sistem resapan dengan tanaman sehingga limbah yang keluar melalui permukiman warga dapat tersaring dan tidak mengotori lingkungan sungai dan mengurangi debit air yang menggenang. Skema sistem bio swale Dapat dilihat pada Gambar 13.
Setelah melalui sistem bio swale, air yang berasal dari air genangan, air limbah, dan air hujan mengalir menuju sungai buatan. Sungai buatan berfungsi sebagai penampung sementara agar debit air yang menggenangi permukiman dapat berkurang. Ketika air sungai buatan telah melebihi batas tampung, air kemudian dialirkan ke sungai melalui pipa yang dapat diatur dengan pintu air.

Area sungai buatan kemudian dapat dikembangkan sebagai area sosial terbuka yang dapat dimanfaatkan sebagai area penanaman tanaman sayur dan area filtrasi air sungai menjadi air bersih.

Sistem pengolahan air bersih menggunakan sistem up-flow yakni dengan metode penyaringan dengan bak penenang dan pasir penyaring. Sistem ini juga dibantu dengan teknologi MERALIS (Membran UF-RO Air Lift System) yakni sistem penyaring air sungai dengan lumpur aktif dan ultrafiltrasi sehingga dapat diolah menjadi air bersih untuk kebutuhan sehari-hari.

Beberapa upaya di atas merupakan penerapan perwujudan poin interactive di mana bangunan dan permukiman harus dapat bersinergi dengan energi lingkungan.

\subsection{Skenario Permukiman}

Permukiman Kampung Kota Vertikal kenteng memiliki skenario permukiman dengan kebijakan hak guna untuk warga Kampung Kenteng yang memiliki KTP Solo dan atau mereka yang telah tinggal di kampung ini selama lebih dari 40 tahun. Sistem ini telah diatur oleh pemerintah dalam Undang-undang pokok argraria No.5 Tahun 1960 mengenai inventaris tanah di seluruh Indonesia.

Skenario permukiman bagi warga yang tidak memiliki KTP Solo menggunakan sistem sewa dengan biaya rendah. Penghuni kampung vertikal tidak dapat menyewakan unit hunian namun dapat menyewa unit modular, dapat dilihat pada Gambar 14.

Sistem pengelompokkan lantai berdasarkan profesi ekonomi industri rumahan. Pengelompokan ini dinilai akan mempermudah dalam pemindahan pengguna dan efisiensi dalam berekonomi. 


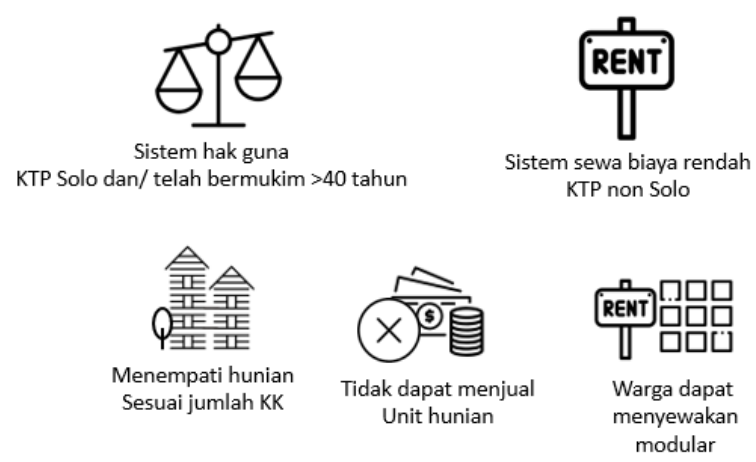

Gambar 14. Skenario Kebijakan

Area akan dibagi menjadi 2 area yakni area 1 yang meliputi RT 3 dan area 2 yang meliputi RT 02,05, dan 06. Area 1 menjadi prioritas pertama dengan tingkat kekumuhan tertinggi.

Perencanaan bangunan akan dilakukan mulai dari area kosong yang beradai di area 1. Area terbangun kemudian ditempati oleh penghuni sekitar dan pembangunan selanjutnya dilakukan di lahan permukiman sekitar yang tidak lagi dihuni. Ritme proses ini berlangsung hingga perencanaan pembangunan selesai.

Penggunaan area kosong ini sebagai efisiensi pembangunan sehingga warga tidak harus berpindah ke hunian lain selama pembangunan. Dapat dilihat pada Gambar 15.
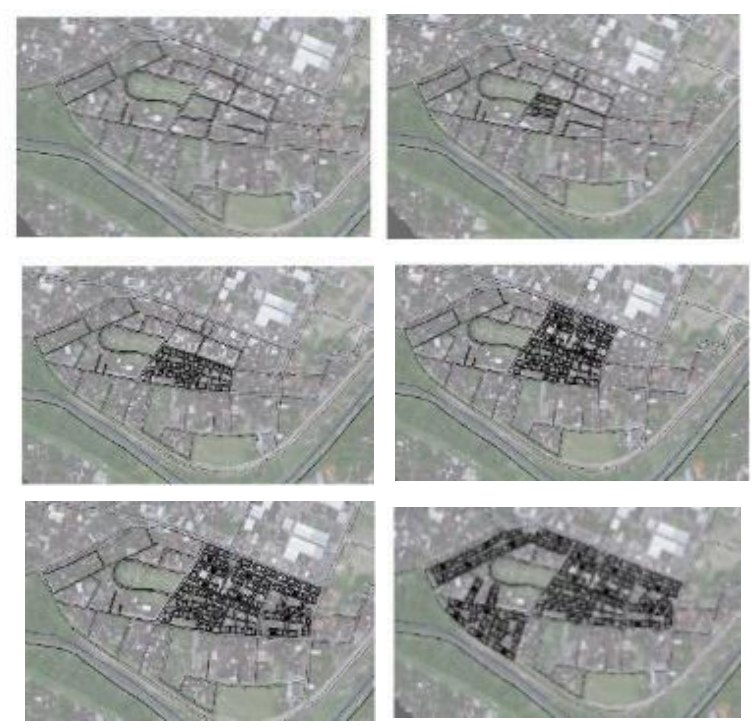

Skenario Tahapan Pembangunan

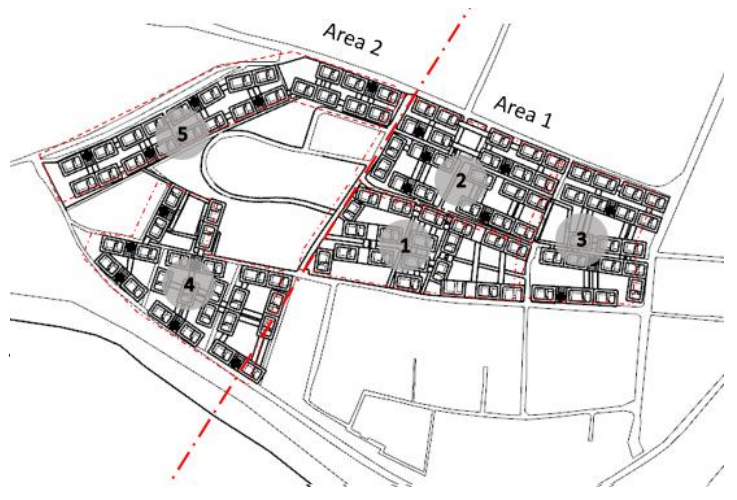

Gambar 15. Skenario Tahapan Pembangunan

\section{KESIMPULAN}

Fleksibilitas dapat dikembangkan sebagai strategi desain untuk menyelesaikan kebutuhan hunian, khususnya hunian di permukiman kumuh Kampung Kenteng dengan keterbatasan lahan dan keterbatasan kepemilikan lahan.

Strategi ini sebagai salah satu upaya dalam menjawab kemungkinan penyesuaian terhadap kebutuhan pengguna, kemungkinan adanya ekspansi atau perubahan.

Fleksibilitas dapat diaplikasikan sebagai strategi desain perencanaan dan perancangan Kampung Kota Vertikal Kenteng Semanggi dapat disimpulkan ke dalam akses dengan menerapkan poin Permeability, versatility, dan legibility dengan akses permukiman yang mudah ditemukan dan mudah di akses bagi pengguna khususnya pejalan kaki. Akses diterapkan dengan pola grid secara horizontal maupun vertikal.

Fleksibilitas juga muncul melalui massa bangunan dengan menerapkan poin Continuity and stability dengan bentuk bangunan memiliki fleksibilitas dalam aliran cahaya matahari dan angin ke setiap sisi bangunan melalui tatanan massa dan perbedaan ketinggian antar massa.

Fleksibilitas pada area ruang, menerapkan poin yang cukup beragam yakni Time cycle and time management, expandibility, moveable, adaptable, dan versatile dengan ruang hunian dapat menyesuaikan kebutuhan, dapat diubah, diperbesar sesuai limitasi yang telah ditentukan, dan multifungsi. 
Penerapan fleksibilitas dalam segin struktur dengan poin Implemented over time, convertibility, dan Transformable. Dengan struktur bangunan yang dapat disesuaikan, dapat berubah mengikuti kebutuhan pengguna, dan efisien dalam segi pembangunan dan penggunaan.

Penerapan dalam segi utilitas dengan menerapkan poin Interactive yakni penyelarasan terhadap energi lingkungan seperti lingkungan bantaran sungai melalui sistem bio-swale dan sungai buatan.

\section{DAFTAR PUSTAKA}

Barathkumar, Aishwarya. 2013. Flexibility Architecture. New Delhi

Bentley, I., Alcock, A., Murrain, P., McGlynn, S., \& Smith, G. (2003). Responsive environment: A Manual for Designers. Translated by Mostafah Behzadfar, Tehran, Elm-o-Saant Press

Carmona, Heath, Oc, Tiesdell. 2003. Public places - urban spaces, the dimension of urban design. Oxford: Architectural press

Dinas Permukiman Surakarta. 2017. Urutan Prioritas Penanganan Permukiman Kumuh., Direktorat Pengembangan Kawasan Permukiman tahun 2016

Direktorat Pengembangan Kawasan Permukiman tahun 2016. Perencanaan \& Perancangan Arsitektur Rumah Susun Sederhana. Jakarta: Pusat Litbang Permukiman.

Toekio. 2000. Dimensi Ruang dan Waktu. Bandung: Intermatra

Yanno, El., Marsudi, dan Kusumaningdyah. 2016. Kalianyar Vertical Kampong With Behavior Architecture In Jakarta. Surakarta: Arsitektura. 